DOI 10.37882/2223-2982.2022.01.39

\title{
ПРАКТИКО-ОРИЕНТИРОВАННЫЕ ЗАДАЧИ КАК СРЕДСТВО ПОВЫШЕНИЯ МОТИВАЦИИ К ИЗУЧЕНИЮ МАТЕМАТИКИ У СТУДЕНТОВ ССУЗОВ
}

\section{PRACTICE-ORIENTED TASKS AS A MEANS OF INCREASING MOTIVATION TO STUDY MATHEMATICS AMONG COLLEGE STUDENTS}

\section{N. Schmidt \\ E. lakhina}

Summary: The article discusses ways to increase motivation to study the discipline "mathematics" among students of specialty 38.02 .02 "Insurance business" through the use of practice-oriented tasks. The study was conducted on the basis of the Novosibirsk State University of Economics and Management. As a result of the work performed, the main requirements for practice-oriented tasks were identified. As examples, practice-oriented tasks on probability theory and mathematical statistics are described, which are based on basic concepts from the professional activities of future insurers: insurance event, insurance risk, insurance tariff, insurance payout, etc. An algorithm for solving practice-oriented tasks is proposed, which assumes a dialog interaction between a student and a teacher as an indispensable condition for effective learning. $A$ survey of students was conducted in order to identify the leading motives of students for vocational training; conclusions were drawn.

Keywords: mathematical training, motivation, motivation for mathematical activity, practice-oriented tasks, algorithm for solving practice-oriented tasks, insurance business.
$\mathrm{M}$ атематическое образование является важной частью любого этапа обучения в рамках современной образовательной системы, в том числе и при подготовке студентов в учреждениях среднего профессионального образования (СПО).

В Концепции развития математического образования в Российской Федерации говорится о том, что «... изучение математики играет системообразующую роль в образовании, развивая познавательные способности человека, в том числе к логическому мышлению, влияя на преподавание других дисциплин. Качественное математическое образование необходимо каждому для его успешной жизни в современном обществе» [1].

Мотивация учения была и остается проблемой, которая остро стоит перед студентами и преподавателями. «Под мотивацией понимается совокупность процессов,
Шмидт Надежда Михайловна к.п.н., дочент, Новосибирский государственный университет экономики и управления «НИНХ»,

2. Новосибирск nad8880@yandex.ru

Яхина Елена Петровна

к.п.н., дочент, Санкт-Петербургский государственный архитектурно-строительный университет,

2. Санкт-Петербург eyakhina@gmail.com

Аннотация: В статье рассматриваются пути повышения мотивации к изучению дисциплины «математика» среди студентов специальности 38.02 .02 «Страховое дело» посредством использования практико-ориентированных задач. Исследование проводилось на базе Новосибирского государственного университета экономики и управления. В результате выполненной работы выявлены основные требования к практико-ориентированным задачам. В качестве примеров описаны практико-ориентированные задачи по теории вероятностей и математической статистике, в основе которых лежат базовые понятия из профессиональной деятельности будущих страховщиков: страховой случай, страховой риск, страховой тариф, страховая выплата и др. Предложен алгоритм решения практико-ориентированных задач, который предполагает диалоговое взаимодействие студента и преподавателя как непременное условие эффективного обучения. Проведено анкетирование студентов с целью выявления ведущих мотивов учащихся к профессиональному обучению; сделаны выводы.

Ключевые слова: математическая подготовка, мотивация, мотивация к математической деятельности, практико-ориентированные задачи, алгоритм решения практико-ориентированных задач, страховое дело.

определяющих движение по направлению к поставленной цели, а также факторы, которые влияют на активность или пассивность поведения человека в различных ситуациях» $[3$, с.44].

Н.А. Мамаева в своем исследовании говорит о том, что мотивация «является одним из наиболее действенных средств повышения эффективности и качества учебного процесса» [4, с. 2].

М.А. Приходько утверждает, что «посредством учебной мотивации можно...достичь требуемого уровня сформированности знаний, умений, навыков и сформировать профессиональные знания, умения, навыки [5, с.5].

Недостаточная мотивации ведет к перманентному состоянию неуспеваемости. Низкая учебная мотивация студентов обусловлена многими причинами, в том чис- 
ле: высокой степенью абстрактности предмета, недооценкой значимости математического образования в целом, большой продолжительностью и трудоемкостью его получения, отсутствием единства теории и практики.

Говоря о мотивации к математике, т.е. математической деятельности, важно учитывать сферу деятельности специалистов. Так, специалист страховой организации должен проводить расчеты тарифных ставок по тому или иному виду страхования в зависимости от набора рисков; применять поправочные коэффициенты (повышающие или понижающие тариф на страхование); рассчитывать коэффициент убыточности страховых операций, влияющий на конечный финансовый результат; выполнять актуарные расчеты в страховании и многое другое. Таким образом, специфика математической составляющей деятельности специалиста страхового дела определена особенностями страховых задач и подходов к их решению.

Под математической подготовкой студентов среднего профессионального образования мы понимаем «подготовку, направленную, на приобретение обучающимися в процессе освоения образовательной программы знаний, умений, навыков и формирование компетенций определенного уровня и объема, позволяющих вести профессиональную деятельность в определенной сфере и (или) выполнять работу по конкретным профессии или специальности» [6, стр. 287].

В результате изучения дисциплины «математика» выпускник специальности 38.02.02 Страховое дело (по отраслям) должен владеть

общекультурными компетенциями:

- организовывать собственную деятельность, выбирать типовые методы и способы выполнения профессиональных задач, оценивать их эффективность и качество (ОК-2);

- принимать решения в стандартных и нестандартных ситуациях и нести за них ответственность (ОК-3);

- осуществлять поиск и использование информации, необходимой для эффективного выполнения профессиональных задач, профессионального и личностного развития (OK-4);

- использовать информационно-коммуникационные технологии в профессиональной деятельности (OK-5).

\section{профессиональными компетенциями:}

- анализировать эффективность каждого канала продаж страхового продукта (ПК 2.4);

- анализировать основные показатели продаж страховой организации (ПК 3.3) [7].

Следовательно, специалист страхового дела должен иметь достаточный уровень математической подготовки для решения прикладных задач в области профессиональной деятельности.

Одним из способов повышения мотивации в процессе обучения математике является использование практико-ориентированных задач.

Под практико-ориентированной задачей мы будем понимать учебную математическую задачу, содержание которой раскрывает теоретические аспекты будущей профессиональной деятельности и позволяет использовать математический инструментарий для выполнения профессиональных задач в данной области и формированию профессиональных компетенций.

Проведенный в ходе данного исследования анализ учебной литературы по математике, рекомендованной для студентов специальностей СПО, показал, что на сегодняшний день в них нет блока практико-ориентированных задач в области страхования. По этой причине для большинства студентов курс математики остается формальным и оторванным от профессиональной деятельности, несмотря на то что теория страхования и экономики содержит обширный материал, который можно использовать в курсе математики, в том числе для составления практико-ориентированных задач.

В результате проведенных исследований мы установили, что практико-ориентированные задачи должны удовлетворять следующим требованиям:

- учитывать реальный уровень теоретических знаний и личный опыт обучаемых с целью обеспечения самостоятельного решения;

- вызывать интерес и быть близкими содержательно к выбранной сфере профессиональной деятельности;

- допускать использование дополнительных материалов: справочную и специальную литературу, учебно-экономическую документацию и др.;

- решение задач должно осуществляться на базе программного обеспечения, например, в пакете Ms Excel;

- включать в себя основные темы дисциплины «математика».

Согласно рабочей программе по дисциплине «математика», специалисты страхового дела изучают основы математического анализа, элементы дискретной математики, линейной алгебры, теории вероятностей и математической статистики. Изучение вышеперечисленных разделов является базой для последующего изучения таких дисциплин, как «информационные технологии в профессиональной деятельности», «экономика организации», «статистика», «страховое дело», «бухгалтерский учет в страховых организациях». 
Особо можно выделить раздел «Элементы теории вероятностей и математической статистики». Именно он позволяет в полной мере показать связь математики с теоретической составляющей будущей профессиональной деятельности специалиста страхового дела, в основе которой лежит вероятностное событие особого рода - страховой случай.

Следует отметить, что раздел с элементами теории вероятностей и математической статистики изучался студентами в школьном курсе. Следовательно, наша задача заключается в систематизации и расширении знаний, полученных в школе, таким образом, чтобы выпускник СПО умел использовать теоретико-вероятностный подход для моделирования реальных ситуаций, анализа, прогнозирования и планирования экономических явлений

Для повышения мотивации к изучению дисциплины математика необходимо добавить к типовым задачам практико-ориентированные. Рассмотрим применение практико-ориентированных задач на примере изучения отдельных тем раздела «Элементы теории вероятностей и математической статистики».

Прежде всего, в начале изучения данного раздела необходимо отметить исторический аспект возникновения теории вероятностей, указав на то, что именно зарождение страхового дела послужило толчком для развития теории вероятностей. Уже в XVIII веке в Западной Европе активно создавались страховые компании, занимавшиеся страхованием судов, а также страхованием от пожаров, несчастных случаев, стихийных бедствий и др.

Как известно, теория вероятностей оперирует специальными понятиями и использует учебные математические модели, исходным понятием которых является случайное событие и испытание. Обычно на занятиях рассматриваются классические примеры: бросание монеты или игральной кости, извлечение шара из урны или карты из колоды, выстрел по цели. На наш взгляд, в обучении будущих специалистов по страховому делу к ним целесообразно добавить и наступление страхового случая.

При решении задач на вычисление вероятности события можно рассмотреть задачу о страховании строений в соответствии с методикой, рекомендованной страховым компаниям для расчетов по рисковым видам страхования.

Задача о страховании строений. Страхование имущества проводится на случай их повреждения или уничтожения в результате следующих событий: пожар (1), авария водопроводных, канализационных сетей и отопительных систем (2), противоправные действия третьих лиц (3), стихийные бедствия (4), наезд транспортного средства, падение деревьев, летательных аппаратов и их обломков на застрахованное имущество (5), внезапное разрушение основных конструкций застрахованного строения (квартиры; нежилого помещения; строения/квартиры), в котором находится застрахованное имущество (6).

Для расчетов потребуется разделить строения на три группы: деревянные - 1-я группа, смешанные - 2-я группа, кирпичные - 3-я группа. По экспертным оценкам была составлена таблица данных по страхованию строений всех трех групп (Табл. 1.).

Таблица 1

Вероятность наступления страхового случая

\begin{tabular}{|c|c|c|c|} 
№ & $\begin{array}{c}\text { вероятность } \\
\text { наступления } \\
\text { страхового события } \\
1 \text { группа }\end{array}$ & $\begin{array}{c}\text { вероятность } \\
\text { наступления } \\
\text { страхового события } \\
2 \text { группа }\end{array}$ & $\begin{array}{c}\text { вероятность } \\
\text { наступления } \\
\text { страхового события } \\
3 \text { группа }\end{array}$ \\
\hline 1 & $q=0.00008$ & $q=0.00007$ & $q=0.00008$ \\
\hline 2 & $q=0.00008$ & $q=0.00008$ & $q=0.00008$ \\
\hline 3 & $q=0.00007$ & $q=0.00006$ & $q=0.00007$ \\
\hline 4 & $q=0.00003$ & $q=0.00003$ & $q=0.00003$ \\
\hline 5 & $q=0.000002$ & $q=0.000002$ & $q=0.000002$ \\
\hline 6 & $q=0.000002$ & $q=0.000002$ & $q=0.000002$ \\
\hline & Страховая сумма: & Страховая сумма: & Страховая сумма: \\
& 3000000 & 5000000 & 8000000 \\
\hline
\end{tabular}

Необходимо провести анализ экспертных данных: найти по каждой группе вероятность ненаступления страхового случая; размер страховой выплаты по каждой группе на случай наступления страхового события.

В ходе обсуждения задачи следует отметить рискориентированный подход в страховании. Для этого нужно обсудить те же показатели, но в регионах страны с повышенными рисками: наводнения (Алтайский край, Иркутская область), стихийных бедствий (Камчатка, о. Сахалин), оползней, селей (Дагестан, Крым) и др.

При изучении числовых характеристик случайных величин можно предложить студентам решить задачу о страховом портфеле. Предварительно важно обсудить вопросы: что такое страховой портфель и его содержание; что понимается под доходностью страхового портфеля.

Задача о страховом портфеле. Страховой портфель ООО СК «Салют» состоит на 70\% из активов А и на $30 \%$ из актива В. Доходность активов А и В равны соответственно $10 \%$ и $12 \%$. Какова ожидаемая доходность страхового портфеля?

Решение. Введем обозначение:Д-доходность, которая является случайной величиной, принимающей два значения: $10 \%$ и $12 \%$. Состав страхового портфеля (70\% и $30 \%)$ 
характеризуется вероятностями 0.7 и 0.3 этих случайных величин. Поэтому ожидаемая доходность находится по правилу вычисления математического ожидания:

$$
M(Д)=10 \cdot 0.7+12 \cdot 0.3=7+3.6=10.6(\%)
$$

Ответ: $10.6 \%$

При изучении предельной теоремы Пуассона в схеме Бернулли мы предлагаем решить задачу о страховании от пожаров.

Задача о страхование от пожаров. В страховой компании ООО «Т-Полис» 500 клиентов застраховали свою недвижимость от пожаров. Страховой взнос 2000 руб., а страховая выплата клиенту в случае пожара составляет 200 тыс. руб. Вероятность пожара в течение года произвольно взятой недвижимости равна 0.005. Найти: а) математическое ожидание прибыли страховой компании. Найти вероятность того, что в течение года: б) будет прибыль; в) прибыли не будет; г) год будет убыточным.

Введем обозначения: $\mathrm{k}$ - число пожаров в течение года, $\mathrm{n}=500$ - число клиентов, $\mathrm{p}=0.005$ - вероятность пожара произвольно взятой недвижимости, Рпр - вероятность прибыли, Руб - вероятность убытка.

Решение. Вероятность k пожаров вычисляется по формуле Пуассона:

$$
P(k)=\frac{a^{k}}{k !} e^{-a}
$$

где $a=n p=2.5 ; e^{-2,5}=0.082$

Страховая компания ООО «Т-Полис» собрала страховых взносов на 2000•500=1 млн. руб.

Если произойдет k пожаров, то страховая компания выплатит возмещение в размере 0.2 k млн. руб., а ее прибыль составит ( 1 - 0.2k) млн. руб. Поскольку математическое ожидание числа пожаров в течение года равно 2.5, то математическое ожидание прибыли страховой компании будет равен: 1 - 0.2·2.5=0.5 млн. руб.

Найдем такое значение числа пожаров, при котором прибыль страховой компании будет нулевой. Из уравнения $1-0.2 \mathrm{k}=0$, имеем $\mathrm{k}=5$, т.е. с числа $\mathrm{k}=5$ компания не будет иметь прибыли.

Вероятность того, что в течение года компания получит прибыль, вычисляется по формуле:

$P_{n p}=\sum_{k=0}^{4} P(k)=\left(\frac{2.5^{0}}{0 !}+\frac{2.5^{1}}{1 !}+\frac{2.5^{2}}{2 !}+\frac{2.5^{3}}{3 !}+\frac{2.5^{4}}{4 !}\right) e^{-2.5}=$

$=(1+2.5+3.125+2.042+1.628) \cdot 0.082=0.844$
Вероятность остаться без прибыли является вероятностью противоположного события:

$$
1-\text { Pnp }=1-0.844=0.156 .
$$

Вероятность понести убытки будет равна:

$P_{y \sigma}=1-P_{n p}-P(5)=0,156-\frac{2,5^{5}}{5 !} e^{-2,5}=0,156-067=0,089$

Ответ: а) 0.5 млн. руб.; б) 0.844; в) 0.156; г) 0.089.

В соответствии с приведенным расчетом, страховая компания ООО «Т-Полис» будет иметь годовую прибыль с довольно высокой вероятностью. Риск оказаться без прибыли оценивается вероятностью 0.156 , а риск понести убытки - вероятностью 0.089. С таким вероятностным прогнозом страховая компания может рассчитывать на успешный бизнес.

Практика решения практико-ориентированных задач включает в себя различные виды учебной деятельности. Студентов необходимо включать в работу по выявлению и формулировке проблемы; по уяснению профессиональной составляющей предложенной задачи; по усвоению новых математических понятий, экономических и специальных терминов теории страхования; по применению математического инструментария и различных методов решения к задачам сопряженных с теорией страхования; по оценке экономических последствий принятия решения.

При решении практико-ориентированных задач можно использовать алгоритм, представленный на рисунке 1.

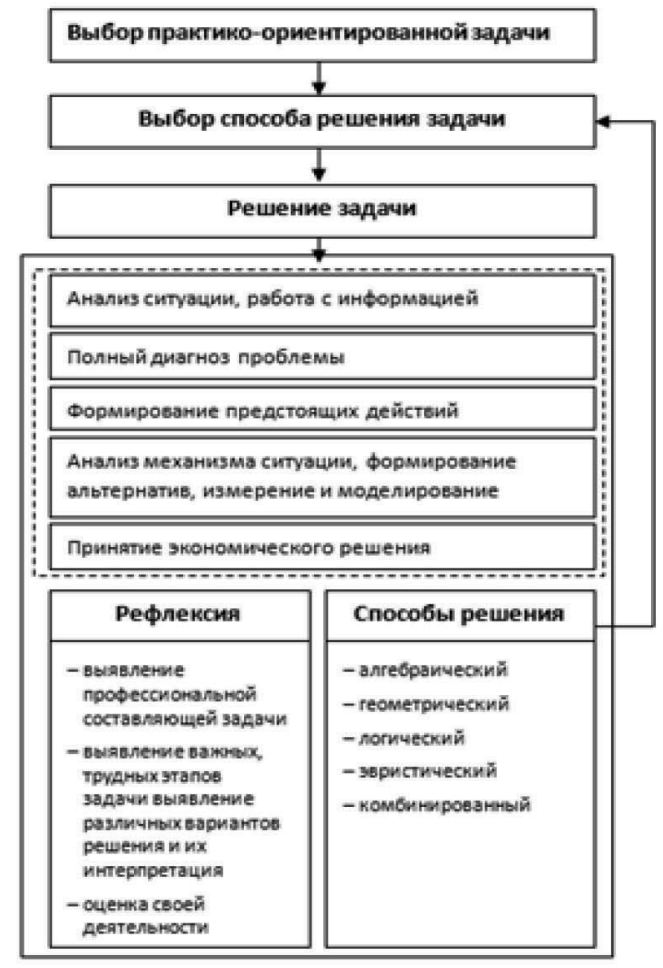

Рис. 1. Алгоритм решения практико-ориентированных задач 
Представленный алгоритм будет эффективным, если педагог и студенты будут работать в диалоговом взаимодействии.

Решение каждой задачи должно сопровождаться разъяснением специфической информации и экономической интерпретацией полученного решения. В ходе решения задач формируется понимание границ применения специфической информации, методик теории страхования и математического инструментария, используемых в практике страхования.

Студенты, обучающиеся в системе СПО, - это молодые люди, которым присуще раннее профессиональное самоопределение, с одной стороны, а с другой - недостаточная социальная зрелость. В условиях стихийно сложившегося дистанционного обучения в течение двух последних лет наблюдается снижение качества математического образования выпускников 9 и 11 классов.

В 2021 году большая часть выпускников 11 классов, поступивших на факультет СПО, не сдавали экзамен по математике в школе (базовый уровень был отменен), а оставшиеся одиннадцатиклассники не сдали профильный уровень по математике. Низкий уровень знаний по математике отмечается на фоне снижения мотивации к обучению, в том числе и к математике.

Для того чтобы выяснить ведущие мотивы учащихся к обучению, мы провели анкетирование среди первокурсников Новосибирского государственного университета экономики и управления (НГУЭУ), поступивших на специальность «страховое дело» в 2020-2021 учебном году. В качестве опросника была использована форма по методике С.С. Груншпун «Мотивы выбора профессии» [2].

Результаты анкетирования показали, что 43\% студен- тов привлекает материальное благополучие и желание заработать, а интересы, склонности или практическая подготовленность учитываются в меньшей степени. Почти треть учащихся (31\%) одним из основных мотивов назвали стремление к творческой работе, интерес к новым технологиям, приобретению необходимых умений и навыков, которые требует профессиональная деятельность. Мотивы выбора престижной профессии преобладают у $26 \%$ опрошенных - для них особенно важно стремление занять видное положение в обществе и реализовать высокий уровень социальных притязаний.

В основном будущие страховщики высоко оценивают востребованность своей специальности на рынке труда. И хотя они достаточно осознанно подходят к выбору профессии, для успешного продолжения учебы, а в дальнейшем и выбора места работы им необходимо повышать мотивацию к учебной деятельности, в частности к математике. Входной контроль по математике, проведенный среди первокурсников специальности «страховое дело», показал средний уровень базовой математической подготовки.

Внедрение элементов теории страхования и экономики в практико-ориентированные задачи наглядно демонстрируют точки соприкосновения математики с профессиональной деятельностью, эффективность использования математического аппарата для исследования страховых событий и актуарных расчетов, которые носят вероятностный характер, требуют поиска решений и самостоятельности мышления в нетипичных ситуациях.

Несомненно, использование в учебном процессе практико-ориентированных задач повышает как интерес к обучению, так и мотивацию к изучению математики, а также способствует формированию профессиональных компетенций учащихся.

\section{ЛИТЕРАТУРА}

1. Распоряжение Правительства Российской Федерации № 2506-р от 24 декабря 2013 года «0б утверждении Концепции развития математического образования в Российской Федерации» [Электронный ресурс] - Режим доступа: http://pravo.gov.ru/laws/?num.

2. С.С. Гриншпун, Оценка личностно-делового потенциала учащихся в профориентационной работе // Школа и производство. - 1994- № 6- С. 11-12.

3. Н.Л. Стефанова, Методика и технология обучения математике. Курс лекций: пособие для вузов / Н.Л. Стефанова, Н.С. Подходова, В.В. Орлов и др.; под науч. ред. Н.Л. Стефановой, Н.С. Подходовой. М.: Дрофа, 2005. -416 с.

4. Н.А. Мамаева, Формирование учебной мотивации студентов технических вузов: автореф. дис. ... канд. пед. наук: 13.00.02 / Мамаева Н.А. Великий Новгород, 2007. $18 \mathrm{c}$.

5. М.А. Приходько, Учебная мотивация как средство управления личностно-ориентированным обучением математике студентов аграрного университета: автореф. дис. ... канд. пед. наук: 13.00.02 / Приходько М.А. Омск, 2008. - 20 с.

6. Н.М. Шмидт, Проблемы современного педагогического образования. Сборник научных трудов: - Ялта: РИО ГПА, 2020. - Вып. 66. - 4.1. - 365 с.

7. Приказ Минобрнауки России от 28.07.2014 N 833 «06 утверждении федерального государственного образовательного стандарта среднего профессионального образования по специальности 38.02.02 Страховое дело (по отраслям)» (Зарегистрировано в Минюсте России 25.08.2014 N 33821) .

8. Б.П. Зеленцов, Вероятностные задачи с экономически содержанием: практикум. - Новосибирск: САФБД, 2007. - 124с.

9. Н.А. Бакшаева, А.А. Вербицкий, Психология мотивации студентов. М. : Логос, 2006. - 184 с. 
10. Д.А. Матвеева, Роль предметов общеобразовательного цикла в профессиональной подготовке студентов ССУЗов // Среднее профессиональное образование. - 2006.- Вып. 12. - С. 10-11.

( Шмидт Надежда Михайловна (nad8880@yandex.ru), Яхина Елена Петровна (eyakhina@gmail.com).
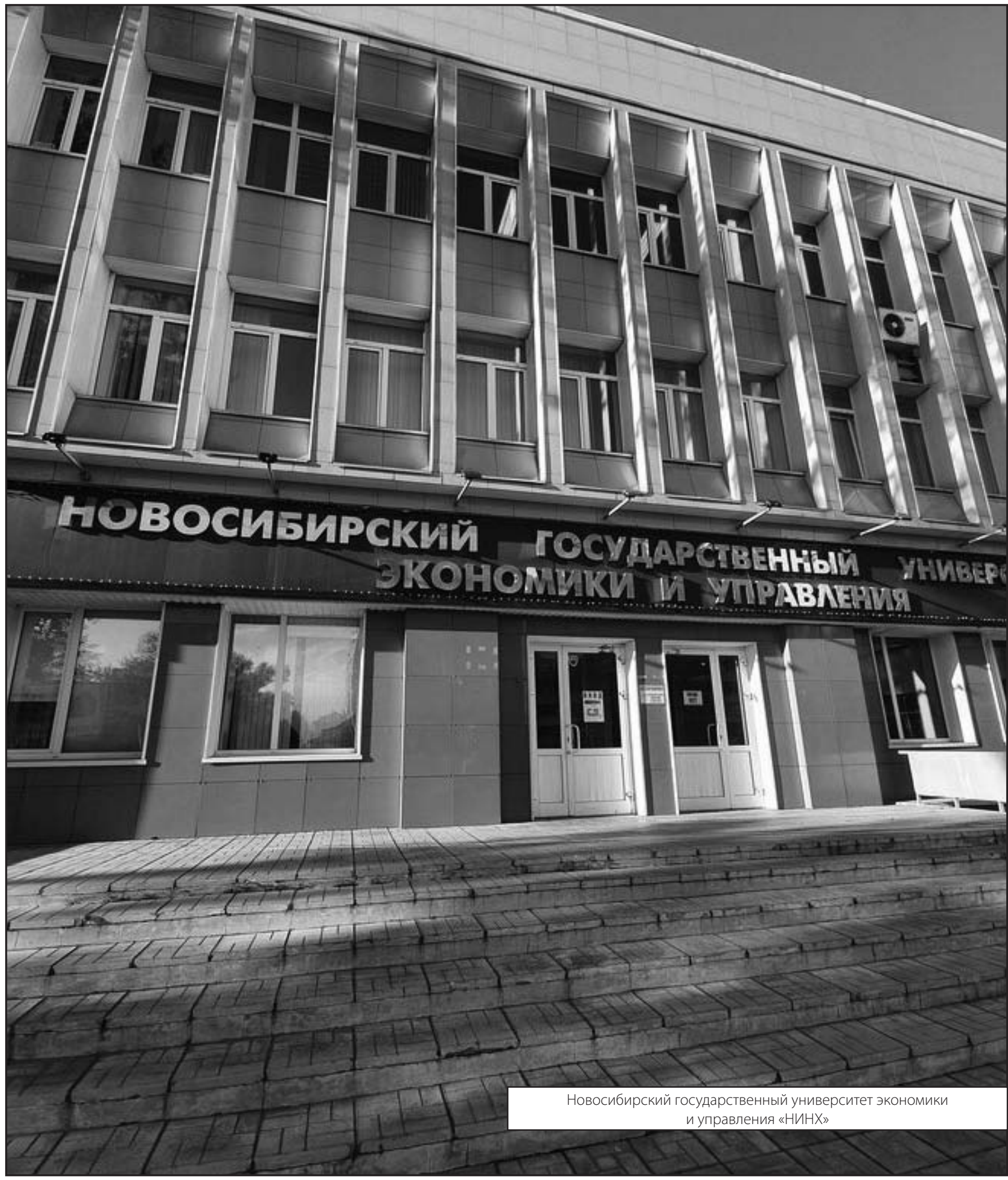